\title{
Prevalence and determinants of low birth weight: the situation in a traditional birth home in Benin City, Nigeria
}

\author{
Henry Bankole Oladeinde ${ }^{1}$, Oladapo Babatunde Oladeinde ${ }^{2}$, Richard Omoregie ${ }^{3}$, \\ Adekunle Abdufattai Onifade ${ }^{4,5}$
}

1. Department of Medical Microbiology, College of Health Sciences, Igbinedion University, Okada, Nigeria.

2. Department of Obstetrics and Gyneocology, Irrua Specialist Teaching Hospital, Irrua, Edo State, Nigeria.

3. School of Medical Laboratory Sciences, University of Benin Teaching Hospital, P.M.B 1111, Benin City, Edo State, Nigeria.

4. Immunology Unit, College of Medicine, University of Ibadan, Nigeria.

5. Faculty of Health and Social Care Sciences, St Georges University of London and Kingston University ,London

\begin{abstract}
Background: The traditional birth attendant delivers majority of pregnant women in Nigeria.

Objective: This study aimed at determining the prevalence and associated risk factors for delivery of low birth weight (LBW) neonates in a Traditional Birth Home (TBH)in Benin City, Nigeria.

Methods: A total of 780 pregnant women who received ante-natal care at a TBH and live singletons born to them were recruited for this study. Venous blood was collected from all pregnant women at onset of labour, and haemogblobin concentration determined using standard method.

Results: The prevalence of low birth weight was $6.3 \%$, and was significantly affected by maternal age $(\mathrm{P}=0.039)$, gestational age $(\mathrm{P}=0.019)$, maternal height $(\mathrm{P}=0.001)$, marital status $(\mathrm{P}=0.015)$, and time of registration $(\mathrm{P}=0.016)$. Being in a polygamous union, was significantly associated with the prevalence of $\mathrm{LBW}(\mathrm{OR}=13.640 ; 95 \% \mathrm{CI}:=6.148,30.261 ; \mathrm{P}=<$ 0.0001). Maternal anaemia was identified as a risk factor for the delivering of $\mathrm{LBW}$ neonates $(\mathrm{OR}=2.797 ; 95 \% \mathrm{CI}=1.555$, 5.029; $\mathrm{P}=0.0001)$.

Conclusion: The prevalence of low birth weight was $6.3 \%$. Intervention by appropriate agencies is advocated to reduce LBW in TBHs in Nigeria.

Keywords: low birth weight, risk factors, TBH, Nigeria.

DOI: http://dx.doi.org/10.4314/ahs.v15i4.10

Cite as: Oladeinde HB, Oladeinde OB, Omoregie R, Onifade AA. Prevalence and determinants of low birth weight: the situation in a traditional birth home in Benin City, Nigeria. Afri Health Sci. 2015;15(4):1123-9. bttp:/ / dx.doi.org/ 10.4314/ abs.v15i4.10
\end{abstract}

\section{Introduction}

Low birth weight (LBW) remains a global health challenge with both short and long term adverse consequences $^{1}$. It is an important indicator of the health status of an infant and a principal factor that determines the infant survival, physical and mental development in

\section{Corresponding author: \\ Henry Bankole Oladeinde, \\ Department of Medical Microbiology, \\ College of Health Sciences, \\ Igbinedion University, Okada, Nigeria. \\ Tel: +2348053096120 \\ E-mail: bamenzy@yahoo.com}

the future ${ }^{2}$. Its etiology is complex and may vary from one setting to another. Delivery of LBW neonates has been associated with pre- term deliveries, anaemia, malnutrition and poor use of orthodox ante-natal services $^{1,3,4}$.These are particularly prevalent in sub-Saharan Africa, where factors such as malaria, poverty, illiteracy and poor accessibility to institutionalized health care facilities are rife. In sub-Saharan Africa, and South Asia, which together account for over half $(57 \%)$ of deliveries in the developing world, up to $65 \%$ of births occur outside hospitals and are predominantly delivered by traditional birth attendants (TBAs) ${ }^{5}$.

A Traditional Birth Attendant (TBA) has been defined as a person who assists mothers during childbirth and 
who initially acquires her skills by delivering babies herself or through apprenticeship to other TBAs. ${ }^{6}$ They are known to form an integral part of most communities, and provide a window to local customs, traditions and perceptions regarding childbirth and newborn-care. ${ }^{6}$ In Nigeria as in most developing countries, the TBAs deliver majority of pregnant women. ${ }^{7}$ While the services provided by TBAs are inevitable and widespread in rural areas due to the lack of/or poor access to orthodox health facilities, ${ }^{5}$ a body of evidence is presently accumulating which suggest that many women in urban areas where physical access and financial barriers to facility based obstetric services are minimal, still choose the services offered by the TBA. ${ }^{8,9,10}$ This trend inevitably results in more children been delivered by TBAs who are known to be largely uneducated, ${ }^{11}$ and often unable to prevent and treat obstetric complications. ${ }^{12}$ More than two-thirds of births are not reported in many parts of Africa, because many deliveries occur at home or in very small clinics. ${ }^{1}$ The TBA may not appreciate the importance of accurate assessment of birth weight of neonates and indeed may not even bother to record it. This neglect of proper documentation of LBW in non-institutionalized health facilities, could lead to gross under-estimation of regional and national prevalence of LBW, especially in developing counties of the world.

Population-based studies that include women that patronize both modern and traditional birth homes are necessary to better appreciate and identify prevailing risk factors for LBW in a developing country. Although, data on the prevalence of LBW neonates abound in Nigeria, to the best of our knowledge none have focused on children born in a Traditional Birth Home (TBH). Against this background, this study therefore focused on determining the prevalence and associated risk factors for the delivery of LBW neonates at a TBH in Benin City, Nigeria.

\section{Materials and methods \\ Study centre}

This cross-sectional study was carried out from December 2010 to April 2012. Target institution was a leading TBH located in a suburban area of Evbotubu Quarters, Benin City, Edo State, Nigeria.

\section{Study population}

A total of 780 pregnant women who received ante-natal care exclusively at a $\mathrm{TBH}$, and live singletons born to them were recruited for this study. The age range of pregnant women was 14 - 42 years. Pregnant wom- en who registered or received care in any orthodox health facility at any time in the course of pregnancy were exempted from study. Delivery of singletons was performed by resident traditional birth attendants. All pregnant women who were not sure of the date of their last menstrual period at time of booking were not included in this study. A structured questionnaire was used to obtain relevant information from volunteer pregnant women on an interview basis. This was sometimes done with Pidgin English and local dialect to aid understanding. Informed consent was obtained from all participating pregnant women and their spouse when necessary. The height of all pregnant women was measured and documented. Height of pregnant women was measured to the nearest 0.1 centimeters. This was done with the preganant woman standing bare-footed against a mounted standiometer (Seca). The weight and gender of all singleton babies born to volunteering pregnant women were recorded at birth. An RGZ -20 baby scale calibrated in grams was used to estimate babies weight. Babies were weighed without clothings. The weighing scale was adjusted to zero before reading off results. The scale was standardized each day before use with known weights. The gestational age at booking was calculated from the last menstrual period (LMP). LBW was defined as birth weight $<2500$ g. ${ }^{13}$ Ethical approval was obtained from the Ministry of Health Edo State. Nigeria.

\section{Specimen collection}

At the onset of labour, five $\mathrm{ml}$ of venous blood was collected from each pregnant woman and dispensed into an Ethylene Diamine Tetra-acetic Acid (EDTA) container. The specimen was mixed, labeled and transported to the laboratory for processing. Hemoglobin concentration was determined using an autoanalyser-Sysmex KX-21 (Sysmex Corporation, Kobe, Japan). Anaemia was defined as hemoglobin concentration $<11 \mathrm{~g} / \mathrm{dl}$ for pregnant women. ${ }^{14}$

\section{Statistical analysis}

The data obtained was analyzed using Chi-square (X2) or Fischer's exact test as appropriate and odd ratio analysis using the statistical software INSTAT ${ }^{\circledR}$ (Graphpad software Inc., La Jolla, CA, USA). Statistical significance was set at $\mathrm{P}<0.05$.

\section{Results}

A total of $49(6.3 \%)$ neonates out of the 780 live singletons recruited weighed $<2500 \mathrm{~g}$. A higher prevalence of LBW was observed among female neonates $(7.9 \%)$, but did not reach statistically significant proportion $(\mathrm{OR}=$ 1.757; 95\% CI $=0.971,3.179 ; \mathrm{P}=0.0870)($ Table 1$)$. 
Table 1: Prevalence of low birth weight neonates.

\begin{tabular}{lccccc} 
Characteristics & N & No. $<\mathbf{2 . 5 k g ( \% )}$ & OR & $\mathbf{9 5 \% C I}$ & P value \\
\hline Gender & & & & & \\
Female & 376 & $30(7.9)$ & 1.757 & $0.971,3.179$ & 0.087 \\
Male & 404 & $19(4.7)$ & 0.574 & $0.317,1.030$ & \\
\hline
\end{tabular}

$\mathbf{N}$ - no tested, OR- odd ratio, CI- confidence interval

The prevalence of low birth weight was observed to significantly associated with the prevalence of LBW be significantly affected by maternal age $(\mathrm{P}=0.039), \quad(\mathrm{OR}=13.640 ; 95 \% \mathrm{CI}:=6.148,30.261 ; \mathrm{P}=<0.0001)$. gestational age $(\mathrm{P}=0.019)$, maternal height $(\mathrm{P}=0.001)$, The prevalence of $\mathrm{LBW}$ was not significantly affected marital status $(\mathrm{P}=0.015)$, and time of registration at by parity $(\mathrm{P}=0.136)$ and educational status $(\mathrm{P}=0.342)$ TBH $(\mathrm{P}=0.016)$. Being in a polygamous union, was of participating pregnant women (Table 2 ).

Table 2: Risk factors for delivery of low birth weight neonates.

\begin{tabular}{|c|c|c|c|c|c|}
\hline Characteristics & $\mathbf{N}$ & No. $<2.5 \mathrm{~kg}(\%)$ & OR & $95 \% \mathrm{CI}$ & $P$ value \\
\hline \multicolumn{6}{|c|}{ Maternal age (years) } \\
\hline $14-18$ & 6 & $2(33.3)$ & & & 0.039 \\
\hline $19-23$ & 110 & $10(9.1)$ & & & \\
\hline $24-28$ & 305 & $19(6.2)$ & & & \\
\hline $29-33$ & 237 & $13(5.5)$ & & & \\
\hline $34-38$ & 98 & $4(4.1)$ & & & \\
\hline$\geq 39$ & 24 & $1(4.2)$ & & & \\
\hline \multicolumn{6}{|c|}{ Gestational age (weeks) } \\
\hline$>37$ & 215 & $21(9.8)$ & 2.076 & $1.152,3.742$ & 0.019 \\
\hline$\geq 37$ & 565 & $28(4.9)$ & 0.481 & $1.152,3.742$ & \\
\hline \multicolumn{6}{|l|}{ Marital status } \\
\hline Unmarried & 186 & $19(10.2)$ & 2.139 & $1.174,3.898$ & 0.015 \\
\hline Married & 594 & $30(5.1)$ & 0.468 & $0.257,0.852$ & \\
\hline \multicolumn{6}{|c|}{ Nature of marriage } \\
\hline Polygamy & 48 & $14(29.9)$ & 13.640 & $6.148,30.261$ & $<0.000$ \\
\hline Monogamy & 546 & $16(2.9)$ & 0.073 & $0.033,0.163$ & \\
\hline \multicolumn{6}{|c|}{ Maternal Height (cm) } \\
\hline$\leq 150$ & 144 & $19(13.2)$ & & & 0.001 \\
\hline $151-156$ & 368 & $21(5.7)$ & & & \\
\hline $157-162$ & 202 & $8(3.9)$ & & & \\
\hline $163-168$ & 46 & $1(2.2)$ & & & \\
\hline$\geq 169$ & 20 & $0(0.0)$ & & & \\
\hline
\end{tabular}

N- no tested, OR-odd ratio; CI-confidence interval. 


\begin{tabular}{|c|c|c|c|c|c|}
\hline Characteristics & $\mathbf{N}$ & No. $<2.5 \mathrm{~kg}(\%)$ & OR & $95 \% \mathrm{CI}$ & $P$ value \\
\hline \multicolumn{6}{|l|}{ Parity } \\
\hline Nulliparous & 193 & $17(8.8)$ & & & 0.136 \\
\hline Primiparous & 266 & $15(5.6)$ & & & \\
\hline Multiparous & 321 & $17(5.2)$ & & & \\
\hline \multicolumn{6}{|c|}{ Time of Registration } \\
\hline $1^{\text {st }}$ Trimester & 103 & $5(4.8)$ & & & \\
\hline \multicolumn{6}{|l|}{0.016} \\
\hline $2^{\text {nd }}$ Trimester & 478 & $23(4.8)$ & & & \\
\hline $3^{\text {rd }}$ Trimester & 199 & $21(10.5)$ & & & \\
\hline \multicolumn{6}{|c|}{ Educational Status } \\
\hline Tertiary & 24 & $0(0.0)$ & & & 0.342 \\
\hline Secondary & 287 & $15(5.2)$ & & & \\
\hline Primary & 403 & $28(6.9)$ & & & \\
\hline None & 66 & $6(9.1)$ & & & \\
\hline
\end{tabular}

Maternal anaemia was identified as a risk factor for the delivering of $\mathrm{LBW}$ neonates $(\mathrm{OR}=2.797 ; 95 \% \mathrm{CI}=$ 1.555, 5.029; $\mathrm{P}=0.0001$ ) (Table 3).

Table 3: Effect of heamoglobin concentration of pregnant women on prevalence of low birth weight neonates.

\begin{tabular}{llclll} 
Characteristics & $\mathbf{N}$ & No. $<\mathbf{2 . 5 k g ( \% )}$ & OR & $\mathbf{9 5 \% C I}$ & P value \\
\hline Hb Conc $(\mathbf{g} / \mathbf{d l})$ & & & & & \\
$<11.0$ & 264 & $28(10.6)$ & 2.797 & $1.555,5.029$ & 0.0001 \\
$\geq 11.0$ & 516 & $21(4.1)$ & 0.358 & $0.199,0.643$ &
\end{tabular}

N- no of pregnant women tested, OR-odd ratio; CI-confidence interval; Hb Conc- heamoglobin concentration.

\section{Discussion}

LBW is a major determinant of infant mortality and morbidity, with prevalence that varies from one geographical region to another. Despite the fact that most TBAs are uneducated, ${ }^{11}$ they are responsible for 60 $-80 \%$ of deliveries in the developing world. ${ }^{8}$ Against this background this study focused on determining the prevalence and associated risk factors for delivery of LBW in a TBH in Benin City, Nigeria. To the best of our knowledge, this is the first attempt at determining the prevalence and associated risk factors for the delivery of LBW neonates at a TBH.

The prevalence of LBW in this study was $6.3 \%$. While reports shows that deliveries attended to by TBAs are commonly associated with adverse maternal and foetal outcomes, ${ }^{15}$ interestingly in this study the prevalence of
LBW was lower than figures obtained in a number of institution based studies in Nigeria. ${ }^{4,16,17}$ It is also lower than the Nigerian national prevalence. ${ }^{18}$ The reason for this is however not clear. However, findings from an earlier Nigerian report shows that babies born to women attending TBHs were less likely to be preterm (a factor which has been severally reported to be associated with LBW) as compared to those born in hospitals. ${ }^{5}$ Lending support to this is a South African study which showed a significantly higher prevalence of LBW among infants born in hospitals as compared to those born at home. ${ }^{19}$ Differences in lifestyle, nutritional status of pregnant women prior to delivery, and other covert or overt morbid conditions may have accounted for the observed variation. TBAs are often unable to prevent or treat obstetric complications. ${ }^{12}$ Thus, many high risk pregnant women with obstetric complications 
may have been referred to institutionalized health care facilities for assistance with delivery. Such referrals may result in more children with medical complications such as LBW to be born in orthodox health care facilities, accounting for the disparity of its prevalence observed in this study.

More than two-thirds of births are not reported in many parts of Africa, because many deliveries occur at home or in very small clinics. ${ }^{1}$ In Nigeria today, no data exist on the prevalence of LBW among neonates born in TBHs. With such paucity of reports on prevalence of LBW in non-institutionalized health care facilities, it is indeed possible that the present Nigerian national LBW prevalence of $14 \%{ }^{18}$ is not a true reflection of the magnitude of the challenge in the country. The millennium development goal four calls for a two -third reduction of under five-year mortality rate by $2015 .{ }^{20} \mathrm{In}$ Nigeria, the TBAs delivers majority of pregnant women. ${ }^{7}$ yet data on birth weight of children born in such centers is missing. This no doubt seriously threatens the validity of national statistics of LBW and further might skew the apparent results of interventions to reduce under- 5 mortality rates by two-thirds in a country like Nigeria where utilization of TBAs by pregnant women is still very common. There is therefore an urgent need for the review of LBW prevalence in Nigeria, with a conscious attempt at capturing and including data from TBHs and other unorthodox birth centers, so as to broaden the understanding of the problem. This would help greatly in the articulation and monitoring of effectiveness of intervention effort at reducing LBW in the general population. Although a higher prevalence of LBW was recorded among female neonates as in other studies, ${ }^{4,16}$ the difference was not statistically significant. This is consistent with an earlier finding. ${ }^{2}$

Maternal age was found to significantly affect LBW, with pregnant women within the age group of 14-18 having the greatest risk. Low maternal age has been associated with LBW in previous studies. ${ }^{16,21}$ Teenage pregnancies are known to be associated with poverty and lack of good education ${ }^{22}$ factors which have also been reported to significantly affect the prevalence of $\mathrm{LBW}^{23,24}$ The classic pattern in many developing countries is that infant girls born with LBW continue to experience growth failure during early childhood and perhaps adolescence, and are most likely to have children at an early age (which further reduces their opportunity to reach an optimal body size with adequate nutrient stores before conception), and thereby give birth to LBW infants. ${ }^{1}$ This may be the situation in our study population, as a report from a recent Nigerian study indicates that women who deliver in TBHs were significantly more likely to be teenagers, and of low or middle social class. ${ }^{5}$ Mothers with preterm deliveries had a significantly increased risk $(\mathrm{OR}=2.076,95 \% \mathrm{CI}=1.152$, 3.742, $\mathrm{P}=0.019)$ of delivering LBW neonates. This is consistent with report from an earlier study. ${ }^{23}$

Being unmarried was significantly associated with the prevalence of LBW neonates. This is in line with a previous finding. ${ }^{23}$ In our study, single pregnant women had a 1-3 fold increased risk of delivering LBW neonates. Lack of socio- economic support may be responsible for this observation. Even among married pregnant women, LBW was significantly affected by polygamy. Polygamy may increase poverty by forcing pregnant women to share limited resources. This in turn could lead to malnutrition, disease spread, which affects delivery of LBW. Maternal height was a significant risk factor for delivery of LBW. This is consistent with findings in other studies. ${ }^{16,25}$ Pregnant women with height $\leq 150 \mathrm{~cm}$ were mostly at risk of delivering LBW neonates. The risk however was found to reduce steadily with increasing height. LBW is associated with lack of/ or infrequent ante-natal follow up. ${ }^{21}$ In this study, late registration for ante natal care was found to significantly increase the prevalence LBW neonates. Data shows that a significant proportion of pregnant women do not begin ante-natal care early in Nigeria. ${ }^{26}$ In this study, 677 pregnant women representing $86.7 \%$ of our study population registered at the TBH outside the first trimester.

The prevalence of maternal anaemia at onset of labour in this study was 33.8\%. Maternal anaemia was identified as a risk factor for LBW. This agrees with a previous report. ${ }^{27}$ Pregnant women with haemoglobin concentration $<11.0 \mathrm{~g} / \mathrm{dl}$ had a $2-5$ increased fold risk of delivering LBW neonates. Two independent Nigerian studies have previously reported high prevalence rates of anaemia among pregnant women attending TBHs. ${ }^{6,28}$ Maternal nutritional factors before and during pregnancy have been reported to account for $>50 \%$ of cases of LBW in many developing countries. ${ }^{1}$ Pregnant women who deliver in TBHs are more likely to be teenagers and of low or middle social class. ${ }^{5}$ This coupled with other conditions such as severe malaria infestation, intestinal parasitic infection and malnutrition among the pregnant women could put them at risk of acquiring 
severe anaemia which in turn may increase risk for delivery of LBW neonates. While significant associations between placental malaria and low birth weight is well documented, ${ }^{29,30}$ this could not be determined in this study as participating pregnant women and resident TBA for cultural reasons did not permit the collection of blood from the expunged placenta. This is an observed limitation in this study.

\section{Conclusion}

In brief, the prevalence of LBW in this study was $6.3 \%$ and was significantly affected by maternal age, maternal height, maternal anaemia, marital status, and late registration at TBH. Government interventions aimed at expanding access to quality and affordable health care services, and preconception counseling and care for young women is strongly advocated. Free distribution of iron-folate supplements and insecticide treated bed nets to pregnant women attending TBHs by relevant intervention agencies, is encouraged to reducing malaria, anaemia and associated sequelea.

\section{Conflict of interest}

The authors did not receive any funding or benefit from any source for this work. Authors have no conflict of interest to declare.

\section{Acknowledgement}

Authors acknowledge with thanks all the pregnant women who participated in this study.

\section{References}

1. Ramakrishnan, U. Nutrition and low birth weight: from research to practice. Am J Clin Nutr 2004; 79(1):1721.

2. Roudbari M., Yaghmaei M., Soheili M. Prevalence and risk factors of low-birth-weight infants in Zahedan, Islamic Republic of Iran. Eastern Mediter Health J 2007; 13(4):838-845.

3. Kidanto HL, Mogren J, Lindmark G, Massawe S, Nystrom L. Risk for preterm delivery and low birth weight are independently increased by severity of maternal anaemia. South Afr Med J 2009; 99: 98-102.

4. Onyiriuka AN. Trends in incidence of delivery of low birth weight infants in Benin City, Southern Nigeria. Niger Postgrad Med 2006; 13(3):189-194.

5. Olusanya BO, Inem VA, Abosede OA. Infants delivered in maternity home run by traditional birth attendants in Urban Nigeria: A community - based study. Health care women Int 2011; 32: 474-491.
6. Oladeinde BH, Omoregie R, Odia I, Oladeinde OB. Prevalence of Malaria and Anemia among Pregnant Women Attending a Traditional Birth Home in Benin City, Nigeria. Oman Med J 2012; 27(3):232-236.

7. Ofili AN, Okojie L. Assessment of the role of traditional birth attendants in maternal health care in Oredo Local Government Area, Edo State, Nigeria. J Comm Med Prim Health Care 2005; 17 (1):55-56.

8. Izugbara C, Ezeh A, Fotso JC. The persistence and challenges of home births: Perspectives of traditional birth attendants in urban Kenya. Health Pol Plan 2009; 24:36-45.

9. Khan Z, Mehnaz S, Khalique N, Ansari MA, Siddiqui AR. Poor peri-natal care practices in urban slums: Possible role of social mobilization networks. Indian J Comm Med 2009; 34:102-107.

10. Olusanya BO, Alakija OP, Inem VA. Non-uptake of facility-based maternity services in an inner-city community in Lagos, Nigeria: An observational study. J Biosoc Sci 2010; 42:341-358.

11. Sadoh AE, Ogungbe RO. Multiple fractures and iatrogenic burns in a newborn due to unskilled delivery: A case Report: Afr J ReprodHealth 2008; 12 (3):197-206.

12. Fatmai Z, Culzer AZ, Kezi AA. Maternal and newborn care: practices and beliefs of traditional birth attendants in Sindh, Pakistan, Eastern Mediterr Health J 2005; 11(1-2):226-232.

13. Guyatt HL, Snow RW. Impact of Malaria during Pregnancy on Low Birth Weight in Sub-Saharan Africa. Clin Microbiol Rev 2004; 17(4):760-769.

14. Oladeinde BH, Omoregie R, Mitsan O, Anunibe JA. Prevalence of HIV and anaemia among pregnant women. North Am J Med Sci2011; 3:548-551.

15. Siziya S, Muula AS, Rudatsikira E. Socio-economic factors associated with delivery assisted by traditional birth attendants in Iraq, 2000. BMC Int Health Hum Right. 2009;9:7.Available at www.ncbi.nlm.nih.gov/ pmc/articles/PMC2680806/. Assessed Feruary 26 2014

16. Amosu AM, Atulomah NOS, Olanrewaju MF, Akintubde TI, Babalola AO, Akinnuga AM et al. Retrospective study of some factors influencing delivery of low birth weight babies in Ibadan, Oyo state, Nigeria. Sci Res Essays 2011; 6(2):236-240.

17. Tongo OO, Orimadegun AE, Akinyinka OO. Utilization of malaria preventive measures during pregnancy and birth outcomes in Ibadan, Nigeria, BMC Pregnancy Childbirth2011;11: 60. [http://www.biomedcentral. com/1471-2393/11/60] 
18. Richard Onalo Kudirat E. Olateju . Trend and Seasonality in Admission and Outcome of Low Birthweight Infants in Gwagwalada-Abuja, Nigeria. Inter J Trop Dis Health 2013; 3(3): 190-198.

19. Richardson BD, Sinwel RE, Rantsho JM, Bac M, Moatshe M. Birth weights of babies born at home in a black rural community of Bophuthatswana, Southern Africa. Arch Dis Child 1983; 58:176-179.

20. Kinney MV, Kerber KJ, Black RE, Cohen B, Nkrumah F, Coovadia $\mathrm{H}$ et al. Sub-saharan Africa's mothers, newborns and children: Where and why do they die?. PLoS Med 2010; 7(6). Available at www.plosmed-

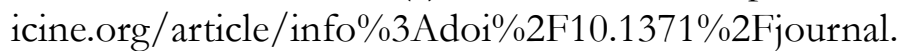
pmed.1000294. Assessed February 17, 2014

21. Zeleke BM, Zelalem M, Mohammed N. Incidence and correlates of low birth weight at a referral hospital in Northwest Ethiopia. Pan Afri Med J. 2012;12:4. PubMed Available at www.ncbi.nlm.nih.gov/pubmed/22826729. Assessed February 17, 2014

22. Desirae MN, Karem HJ. Adolescent pregnancy in America: causes and responses. J Voc Spec Needs Edu 2007; 30(1):1-12.

23. Siza JE. Risk factors associated with low birth weight of neonates among pregnant women attending a referral hospital in northern Tanzania. Tanzan J Health Res 2008; 10(1): 1-8.
24. Lee BJ, Lim SH: Risk of low birth weight associated with family poverty in Korea. Children. Youth Ser Rev 2010; 32 (12):1670-1674.

25. Deshpande JD, Phalke DB, Bangal VB, Peeyuusha D, Sushen B. Maternal risk factors for low birth weight neonates: a hospital based case-control study in rural area of western Maharashtra, India. Nat J Comm Med 2011; 2:394-398.

26. Okunlola MA, Owonikoko KM, Fawole B, Adekunle AO. Gestational age at antenatal booking and delivery outcome. Afr J Med Med Sci 2008; 37(2):165-169.

27. Mbazor OJ, Umeora, OUJ. Incidence and risk factors for low birth weight among term singletons at the University of Benin Teaching Hospital (UBTH), Benin City, Nigeria. Niger J Clin Pract 2007; 10(2):95-99.

28. Idowu OA, Mafiana CF, Dapo S. Anaemia in pregnancy: a survey of pregnant women in Abeokuta, Nigeria. Afr Health Sci 2005; 5(4):295-299.

29. Sarr D, Marrama L, Gaye A, Dangou JM, Niang M, Mercerreau- Puijalon $O$, et al. High prevalence of placental malaria and low birth weight in Sahelian periurban area. Am J Trop Med Hyg 2006; 75 (1): 171-177. 30. Van Spronsen JHM, Schneider TAJ, Atasige S. Placental malaria and the relationship to pregnancy outcome at Gushegu District Hospital, Northern Ghana. Trop Doc 2012; 42(2):80-84. 